\title{
Menopausal hot flushes after breast cancer
}

\author{
D.R. FENLON, PHD, RGN \& SENIOR ReSEARCH Fellow, School of Nursing $\uplus$ Midwifery, University of Southampton, \\ Highfield, Southampton J.L. CORNER, PHD, RGN, PROFESSOR OF CANCER NURsing, School of Nursing e Midwifery, \\ University of Southampton, Highfield, Southampton, \& J. HAVILAND, MSC, statistician, Clinical Trials and \\ Statistics Unit (ICR-CTSU), Section of Clinical Trials, Institute of Cancer Research, Sutton, Surrey, UK
}

\author{
FENLON D.R., CORNER J.L. \& HAVILAND J. (2009) European Journal of Cancer Care 18, 140-148 \\ Menopausal hot flushes after breast cancer
}

\begin{abstract}
The study aimed to improve understanding of the natural history and impact of hot flushes after breast cancer. Data were collected from women participating in an RCT of relaxation to reduce the incidence of flushes from breast cancer follow-up clinics from two hospitals in South-East England. Repondents were 150 women experiencing hot flushes following completion of primary treatment for breast cancer. This study utilized a flush diary, the Hot Flushes and Night Sweats Questionnaire (HFNSQ), Functional Assessment of Cancer Therapy with Endocrine Subscale (FACT-ES) and Spielberger State/Trait Anxiety Index (STAI) as the main outcome measures. The study found that in this sample, $51(34 \%)$ women experienced flushes more than five years after diagnosis and $75(50 \%)$ more than 5 years after menopause. Sleep disruption occurred in 90 women ( $72 \%$ of those that returned diaries), affecting half of the nights they recorded. The mean problem rating on the HFNSQ was 4.85 out of 10. A peak incidence of flushes was apparent around 10 a.m. in women taking tamoxifen. It was concluded that hot flushes after breast cancer may be long-lasting and cause sleeping difficulties for many women. Tamoxifen may affect the diurnal pattern of flushes. After breast cancer, the duration of flushes, potential distress and disruption to women's lives should not be underestimated and appropriate interventions should be offered.
\end{abstract}

Keywords: breast cancer, menopause, hot flushes/flashes, tamoxifen, chemotherapy.

\section{INTRODUCTION}

Due to the role of oestrogen in promoting breast cancer growth (Mokbel 2001), many treatments for breast cancer suppress oestrogen levels, resulting in menopausal problems, and, in particular, hot flushes. As a result, hot flush treatments, which raise oestrogen levels, including hormone replacement therapy (HRT), are contraindicated in women who have had breast cancer (Xydakis et al. 2006). It is well documented that up to $70 \%$ women experience disabling hot flushes after treatment for breast cancer (McPhail \& Smith 2000; Harris et al. 2002;

Correspondence address: D.R. Fenlon, School of Nursing \& Midwifery, University of Southampton, Highfield, Southampton SO17 1BJ, UK (e-mail: dfenlon@soton.ac.uk).

Accepted 23 October 2007

DOI: $10.1111 / j .1365-2354.2007 .00902 . x$

European Journal of Cancer Care, 2009, 18, 140-148
Carpenter \& Andrykowski 1999). While the incidence of flushes may be as much as $52 \%$ in peri-menopausal women without breast cancer (Dennerstein et al. 2000), in women with breast cancer flushes are not only more likely, but they are exacerbated by a lack of safe and effective management strategies (Harris et al. 2002).

Faced with this problem, women need to have an understanding of the course and causes of flushes in order to make informed choices about treatment options. Currently, little is known about the long-term course of recovery from treatment for primary breast cancer, and advice on recovery is not based on scientific data (Stanton et al. 2005). Information about the course of flushes following breast cancer treatment is also lacking. Women cannot be told how long flushes will last, when and whether the severity will subside, what treatments they should take and for how long treatment should be taken. There are some non-hormonal treatments available, such 
as venlafaxine (Barton et al. 2002; Evans et al. 2005) and paroxetine (Stearns et al. 2003), which are reported to be successful in reducing flushes. However, there may be unpleasant side effects (van Gool et al. 2005), and many women prefer not to take drugs, but to manage menopausal flushes by self-help strategies (Shen et al. 2002). Better information about this phenomenon may improve coping and inform the development of techniques to facilitate women's coping with this difficult symptom.

In this paper, we present data on hot flushes from a study of 150 women with breast cancer participating in a randomized controlled trial (RCT) of relaxation training to reduce the incidence of hot flushes. The results of the RCT are presented elsewhere (Fenlon 2007). This paper reports information gathered from these women about the course, nature and impact of hot flushes they were experiencing.

\section{PATIENTS}

Participants in the study were recruited from breast cancer follow-up clinics from two hospitals in South-East England. Women were invited to participate if they were post-menopausal, diagnosed with non-metastatic breast cancer and suffering from menopausal hot flushes. Postmenopausal was defined as 6 months without menstruation. This criterion led to the inclusion of some women for whom menstruation returned at a later date, but was chosen so that women who were suffering from chemotherapy-induced menopause would not be excluded from the study. The women were also required to be able to complete written records in English. Women using HRT or other hormone therapies other than tamoxifen were excluded. Those taking remedies or prescription medicines likely to have an impact on hot flushes, such as acupuncture (Cohen et al. 2003), venlafaxine or progesterones were also excluded. Ethical approval was given by the local hospital ethics committee and written consent was obtained from participants.

During a 1 month audit of recruitment, it was found that $68 \%$ women approached were experiencing hot flushes. Of these, $61 \%$ chose not to enter the study, as they either did not consider their flushes severe enough to warrant involvement in a clinical trial $(37 \%)$, or flushes were severe enough for the women to choose active treatment over trial entry $(24 \%)$. One hundred and fifty women were recruited into the study, and demographic and treatment details are given for these women. However, 25 withdrew before returning baseline data and so data on flushing is described for 125 women. A further 21 withdrew before completing data at 1 month (11 in treatment group and 10 in control group), and a further seven before the third month (four in the treatment group and three in control). Reasons for withdrawal from the study were varied, and ranged from family reasons, holidays, illness and being too busy to not wanting to be reminded of having had cancer.

\section{METHODS}

In the main study, from which data reported here were taken, women attending the clinics were asked if they were experiencing hot flushes and whether they would be interested in taking part in a trial to see if relaxation training could reduce flushes. Those recruited into the study were asked to complete baseline measures and were then randomly allocated to receive relaxation training or to be in a control group.

\section{Measures}

Demographic and medical data were gathered from the participants during the consent process. The incidence of flushes was measured using a diary, kept by the women, of every flush as it occurred over the period of 1 week. These 1 -week diaries were completed at baseline, 1 month and 3 months. Diaries have been recommended for use in hot flush research by a number of researchers (Sloan et al. 2001; Miller \& Li 2004). The women also gave a measure of the severity of each flush using pre-defined categories based on work by Finck et al. (1998), who defined hot flushes using interviews gathered from women with breast cancer. There was also a separate question which asked women if their sleep had been disturbed and to give an estimate of how much sleep they had lost.

The distress caused by flushing was measured using the Hot Flushes and Night Sweats Questionnaire (HFNSQ) (Hunter \& Liao 1995). Women scored from 0 to 10, where 0 was no problem and 10 was very much a problem, on three problem-rating scales: the extent to which the symptoms are distressing, interfere with life, and are a problem. We also collected data on quality of life using the Functional Assessment of Cancer Therapy with the endocrine subscale (FACT-ES) (Brady et al. 1997; Fallowfield et al. 1999), and anxiety, which was measured using the Spielberger State/Trait Anxiety Index (STAI) (Spielberger 1983). All measures were completed at baseline, and at 1 and 3 months after relaxation training. Data presented here were collected at baseline unless otherwise specified.

\section{Analysis}

Data relating to demographics and treatments were analyzed using descriptive statistics. Summary statistics were 
provided on the number and severity of hot flushes as described in the diaries. There were four domains of severity and each was graded $0-4$. This gave a maximum possible score of 16 per flush and a minimum of one. The median severity per flush was used in calculations. Nonparametric statistics were used for analysis of flushes as the distributions were skewed. Spearman correlations were used to test whether there were any associations between flushes and age, state and trait anxiety, marital status, time since diagnosis, and time since last menstruation. The Mann-Whitney $U$-test was used to explore whether there were differences in the number or severity of flushing due to previous treatment. Change in the number and severity of hot flushes over time was tested using the Wilcoxon test for paired data. In order to allow for multiple testing, the significance level was set at 0.01.The diurnal rhythm of hot flushes was observed by plotting a simple bar chart of number of flushes recorded during each hour of the day. Some women claim that the timing of taking tamoxifen affects the occurrence of flushes and so this relationship was explored by plotting the data for tamoxifen and non-tamoxifen users separately.

The FACT-ES and STAI questionnaires were summed according to instructions in the relevant handbooks (Spielberger 1983; Fallowfield et al. 1999). Analysis was conducted using parametric statistics for these and the HFNSQ in order to be consistent with published data (Fallowfield et al. 2004; 2006; Hunter et al. 2004; Schreier \& Williams 2004; Williams \& Schreier 2004).

\section{RESULTS}

This paper reports data on the patterns of flushing reported by the women in the study, including incidence, severity, diurnal patterns, and time since diagnosis or since menopause. It also reports on the impact of flushes on the women's lives, including sleep disruption and quality of life, and the relationship with state and trait anxiety.

The age range was 35-77 years (median 55). Further demographic and treatment details are given in Table 1. Twenty-eight $(18 \%)$ women were taking putative remedies for hot flushes, such as herbal supplements (mostly evening primrose oil or star flower oil) or dietary changes. As there is no convincing evidence of the efficacy of these remedies in reducing incidence of hot flushes, they were not treated as exclusion criteria. They were equally distributed between the control and treatment groups.

Over a third of the women $(51,34 \%)$ in this study had been diagnosed more than 5 years ago and half $(75,50 \%)$
Table 1. Demographic and treatment details

\begin{tabular}{|c|c|c|}
\hline Variable & Category & $\begin{array}{l}\text { Total } \\
\text { sample } n(\%)\end{array}$ \\
\hline Age group & $\begin{array}{l}30-39 \\
40-49 \\
50-59 \\
60-69 \\
70+\end{array}$ & $\begin{aligned} 2 & (1) \\
20 & (13) \\
92 & (61) \\
33 & (22) \\
3 & (2)\end{aligned}$ \\
\hline Marital status & $\begin{array}{l}\text { No current partner } \\
\text { Married } \\
\text { Partner } \\
\text { Missing data }\end{array}$ & $\begin{aligned} 37 & (25) \\
95 & (63) \\
13 & (9) \\
5 & (3)\end{aligned}$ \\
\hline Ethnic origin & $\begin{array}{l}\text { Afro-Caribbean } \\
\text { Asian } \\
\text { Caucasian } \\
\text { Other (inc. mixed race) }\end{array}$ & $\begin{aligned} 2 & (1) \\
2 & (1) \\
143 & (95) \\
3 & (2)\end{aligned}$ \\
\hline Time since & Less than 2 years & $53(35)$ \\
\hline Diagnosis & $\begin{array}{l}2-5 \text { years } \\
\text { Over } 5 \text { years }\end{array}$ & $\begin{array}{l}46(31) \\
51(34)\end{array}$ \\
\hline $\begin{array}{l}\text { Time since last } \\
\text { menstruation }\end{array}$ & $\begin{array}{l}\text { Less than one year } \\
1-2 \text { years } \\
2-5 \text { years } \\
\text { More than } 5 \text { years }\end{array}$ & $\begin{array}{ll}18 & (12) \\
23 & (15) \\
34 & (23) \\
75 & (50)\end{array}$ \\
\hline Currently taking & Yes & $83(55)$ \\
\hline Tamoxifen & No & $67(45)$ \\
\hline Had chemotherapy & $\begin{array}{l}\text { Yes } \\
\text { No }\end{array}$ & $\begin{array}{l}74(49) \\
76(51)\end{array}$ \\
\hline Had oophorectomy & $\begin{array}{l}\text { Yes } \\
\text { No }\end{array}$ & $\begin{array}{r}16(11) \\
134(89)\end{array}$ \\
\hline $\begin{array}{l}\text { Taking any other } \\
\text { treatment or } \\
\text { medication }\end{array}$ & $\begin{array}{l}\text { Yes } \\
\text { No }\end{array}$ & $\begin{array}{ll}58 & (39) \\
92 & (61)\end{array}$ \\
\hline Currently taking & Yes & $12(8)$ \\
\hline Levothyroxine & No & $138(92)$ \\
\hline $\begin{array}{l}\text { Other remedies for hot } \\
\text { flushes }\end{array}$ & $\begin{array}{l}\text { Yes } \\
\text { No }\end{array}$ & $\begin{array}{r}28(19) \\
122(81)\end{array}$ \\
\hline
\end{tabular}

had undergone their last menstruation more than 5 years ago (Table 2). There were 35 (23\%) women with flushes who had undergone both menopause and breast cancer over 5 years ago. In those women taking tamoxifen, most of the women $(38,95 \%)$ had been diagnosed within 5 years. This would be expected as tamoxifen is prescribed for 5 years.

\section{Number and severity of flushes}

The number of flushes experienced by women in this study was highly variable, ranging from 1 to 30 flushes per day (3-176) per week, with a median of five flushes per day (33 per week). Two women recorded over 20 flushes every day for a whole week. Of a maximum score of 16 for severity per flush, taken from the diaries, the median score was 5 . There was a small, but statistically 
Table 2. Numbers of women by treatment by time since diagnosis and time since last menstruation

\begin{tabular}{|c|c|c|c|c|c|c|c|c|c|}
\hline \multirow[b]{2}{*}{ Treatment } & \multicolumn{4}{|c|}{ Time since diagnosis (years) } & \multicolumn{5}{|c|}{ Time since last menstruation (years) } \\
\hline & $<2$ & $2-5$ & $>5$ & Total & $<1$ & $1-2$ & $2-5$ & $>5$ & Total \\
\hline Tamoxifen only & $22(15 \%)$ & $16(11 \%)$ & $2(1 \%)$ & $40(27 \%)$ & $3(2 \%)$ & $6(4 \%)$ & $9(6 \%)$ & $22(15 \%)$ & $40(27 \%)$ \\
\hline Chemotherapy only & $7(5 \%)$ & $3(2 \%)$ & $21(14 \%)$ & $31(21 \%)$ & $5(3 \%)$ & $3(2 \%)$ & $3(2 \%)$ & $20(13 \%)$ & $31(21 \%)$ \\
\hline $\begin{array}{l}\text { Neither tamoxifen nor } \\
\text { chemotherapy }\end{array}$ & $4(3 \%)$ & $8(5 \%)$ & $24(16 \%)$ & $36(24 \%)$ & $3(2 \%)$ & $5(3 \%)$ & $8(5 \%)$ & $20(13 \%)$ & $36(24 \%)$ \\
\hline
\end{tabular}

Table 3. Mean HFNSQ problem rating score (score out of 10)

\begin{tabular}{lcl}
\hline & Hot flushes $(\mathrm{SD})$ & Night sweats (SD) \\
\hline Problem & $5.8(2.33)$ & $5.78(2.48)$ \\
Distress & $4.86(2.38)$ & $5.08(2.53)$ \\
Interference to daily life & $3.38(2.55)$ & $4.27(2.72)$ \\
Mean overall problem & $4.85(2.21)$ & $5.04(2.37)$ \\
$\quad$ rating & & \\
\hline
\end{tabular}

HFNSQ, Hot Flushes and Night Sweats Questionnaire.

significant correlation between the number of flushes and the severity of flushing $(0.24: P<0.01)$. There were no significant correlations between incidence or severity of flushes recorded and age, marital status, time since diagnosis or time since menopause. The mean overall problem rating on the HFNSQ was $4.85(\mathrm{SD}=2.2)$ for daytime flushes and $5.04(\mathrm{SD}=2.4)$ for night sweats on a 10-point scale. The component parts of these scores are given in Table 3.

There were no differences in the number or severity of flushes with use of tamoxifen or chemotherapy (Table 4). There was an apparent correlation in the number of flushes experienced by women who were taking 'other medications'. This was a non-specific category to allow women to list any medications they were taking. On reexamining the data, this category included a wide range of very different medications, such as paracetamol, ibuprofen and frusemide, and no individual candidate could be identified which might have contributed to this phenomenon. None of the medications were associated with flushing, and none were common among the group. The most frequently noted prescribed medicine was levothyroxine, being used by $12(8 \%)$ of the sample, but there was no difference in flushing between those who were and who were not using levothyroxine.

\section{Diurnal patterns}

Broadly speaking, there was little clear evidence of a diurnal pattern in flushing. There was a low incidence of flushes between midnight and $06.00 \mathrm{~h}$. There was then a rise which continued throughout the whole day until midnight. However, there did appear to be a marked peak between 10.00 and $11.00 \mathrm{~h}$ in those women taking tamoxifen (see Figs. 1 and 2). Over the course of the whole study, 298 flushes were recorded at this time in women not taking tamoxifen, and 394 (24\% more) flushes in those who were taking tamoxifen.

\section{Change over time}

The number of flushes was monitored in those women who entered the trial but who did not receive the intervention. In this group, the number of flushes were reduced in over 3 months from a median of 37 to 31.5 flushes per week, and from a median severity of 4.7 to 4.2 , but these changes were not significant.

\section{Loss of sleep}

Disturbed sleep was recorded by $72 \%(n=90)$ women. Over the course of the study, $36 \%$ of recorded nights were disrupted, equating to half of the nights of those women experiencing disrupted sleep. Lost sleep ranged from a few minutes to $6 \mathrm{~h}$, with a median of $30-44 \mathrm{~min}$. In $38 \%$ $(n=280)$ of nights that were disrupted, over 1 hour's sleep was lost. For those who experienced them, night sweats appeared to have a greater impact than hot flushes on everyday life, as they recorded a mean score of 4.27 on the HFNSQ for this factor (see Table 3).

\section{Relationship between anxiety and flushing}

It was proposed that there might be a link between anxiety and flushing, either in relation to incidence and severity, or as a predictor of who would respond to relaxation training. The mean state anxiety at baseline was 37.1 (SD 10.7) and the mean trait anxiety was 40.2 (SD 9.9), where a higher number indicates more anxiety (Table 5). This is similar to norms given by Spielberger (1983) for perimenopausal women (Table 5), although high when compared with women of the same age. When comparing these data with women during treatment for breast cancer, it appears that both state and trait anxiety are 
FENLON et al.

Table 4. A comparison of number and severity of flushes with different treatments $(n=125)$

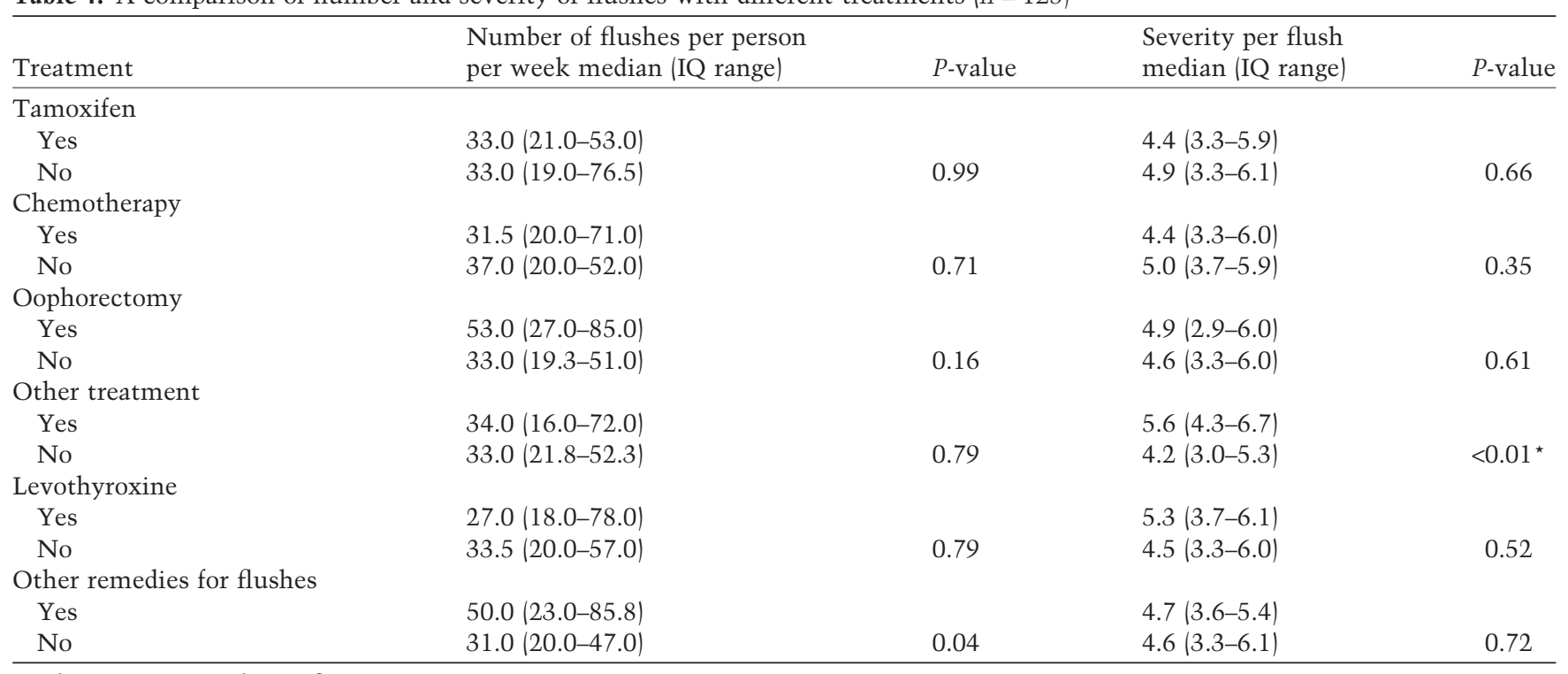

*indicates statistical significance.

$P$-values relate to two-tailed Mann-Whitney test.

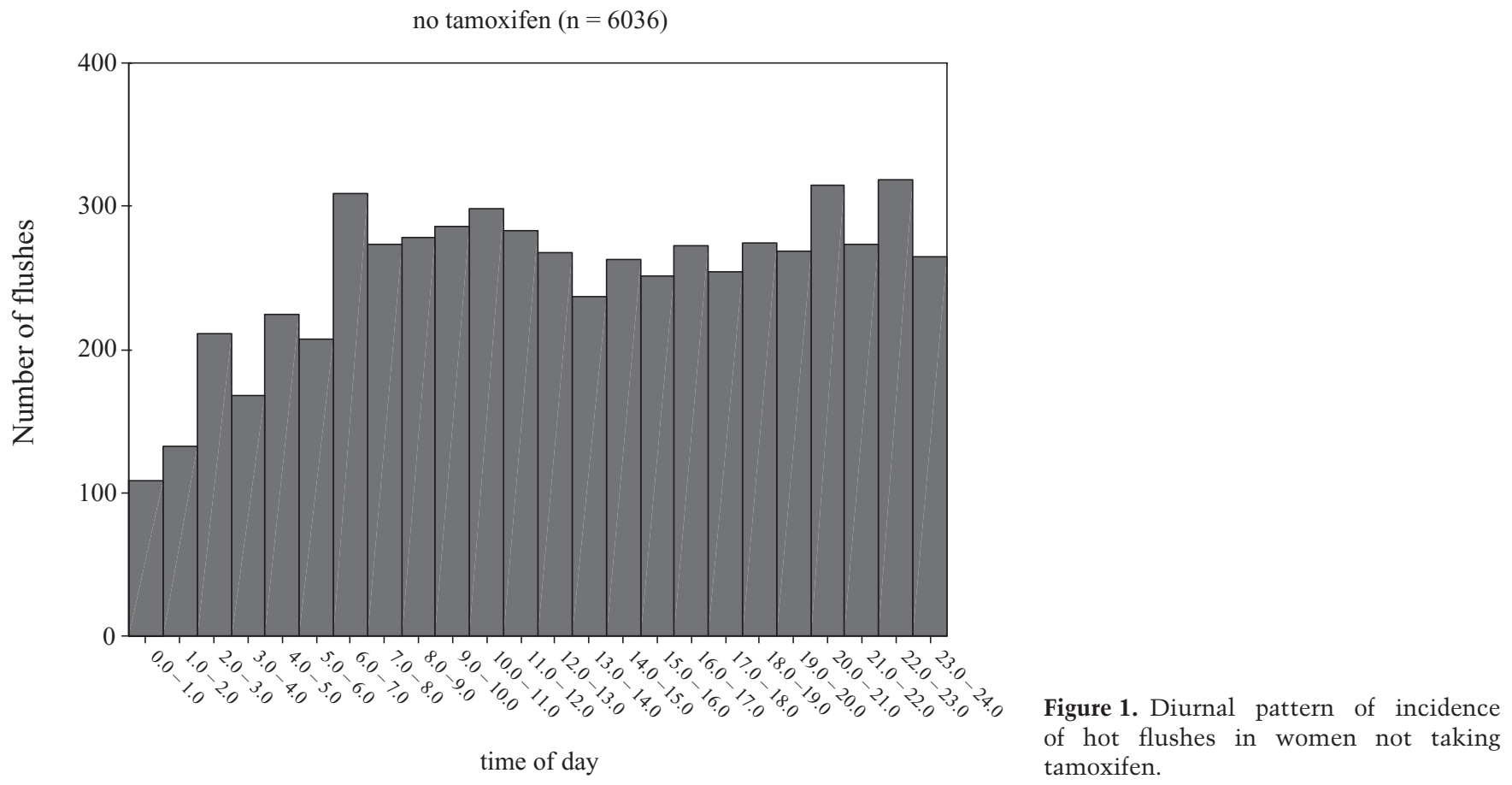

broadly similar to those on active treatment (Schreier \& Williams 2004).

There was a small, but significant correlation between the severity of flushing and state anxiety $(0.29: P<0.01)$, but not trait anxiety. There was no correlation between the number of flushes and either state or trait anxiety (Table 5).

\section{Quality of life}

The FACT-ES quality of life scores are given in Table 5 and compared with previous data published by Fallowfield et al. (1999). The mean quality of life (163.5) was poorer in this sample than for other women with breast cancer, including those taking adjuvant tamoxifen or those under- 
Figure 2. Diurnal pattern of incidence of hot flushes in women taking tamoxifen.

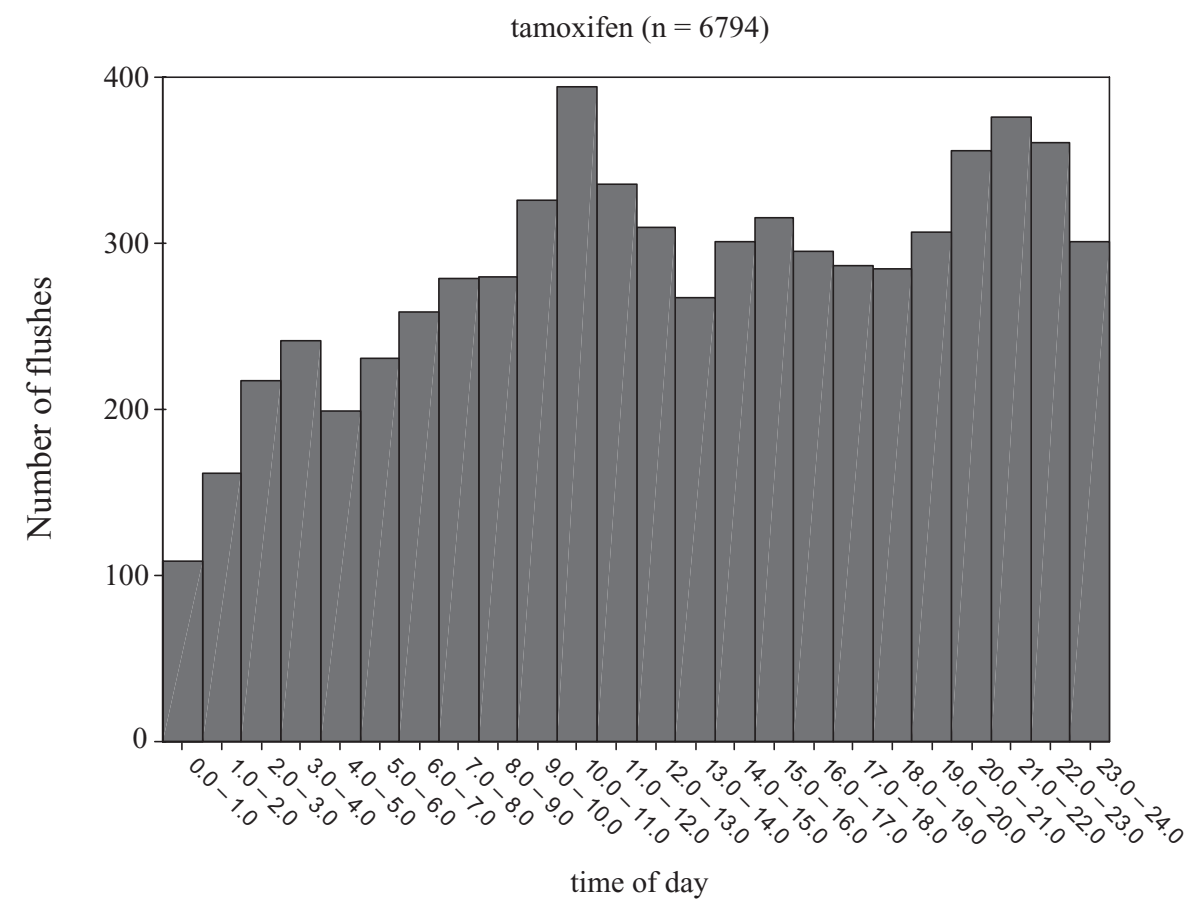

going chemotherapy. In most sub-domains, the quality of life of this group was broadly similar to other groups, except for the endocrine subscale, which asks specific questions about endocrine related symptoms, including hot flushes, where quality of life was lower.

\section{DISCUSSION}

Previous figures published for hot flushes in women taking tamoxifen for breast cancer showed an average of 20.3 per week and mean problem rating of 4.79 (SD 3.1) (Hunter et al. 2004). The women in the current study experienced more flushes and found them more problematic, despite the fact that many of these women had undergone menopause many years earlier. Fifty per cent of this sample had their last menstruation more than 5 years previously.

There has been an assumption among health care professionals that flushes reduce over time and are expected to stop on cessation of tamoxifen use after 5 years. Data from this trial indicate that flushes may be much more long-lasting, causing a problem more than 5 years from diagnosis in over a third of this sample of women. Half of the women had undergone their last menstruation more than 5 years ago. For some women, flushes may have returned following previous natural menopause due to cancer treatment, such as tamoxifen. As further evidence that flushes are long-lasting, no correlations were seen in the number or severity of flushes with either time since diagnosis or time since last menstruation, and, without intervention, no significant reduction was seen in flushes over 3 months. Hunter et al. (2004) have previously reported that hot flushes are persistent in women taking tamoxifen. However, $45 \%$ of our sample were no longer taking tamoxifen and so hot flushes are shown to be a problem for many women post-breast cancer, not only those on tamoxifen.

The relative lack of diurnal pattern has been reported elsewhere (Carpenter et al. 2001). In this trial, there appeared to be slightly more flushes in the early morning and late evening, with few occurring at night. It is possible that in a proportion of cases, flushes occurred at night during sleep but did not cause women to wake. This may highlight the limitations of the diary method. Research, which requires precise measures of occurrence, may need to use external measures. The use of objective measurement of hot flushes has been debated and external skin conductance has been used to measure hot flush incidence more reliably (Carpenter et al. 2004). However, objective measures may not accurately capture the distress caused to women, and it is recommended that both objective and subjective measures of flushes are needed (Miller \& Li 2004). In this trial, the impact on women's lives was the focus and therefore the experience as recorded by the women was of more importance.

The marked peak between 10.00 and $11.00 \mathrm{~h}$ in women taking tamoxifen has not been reported elsewhere. The 


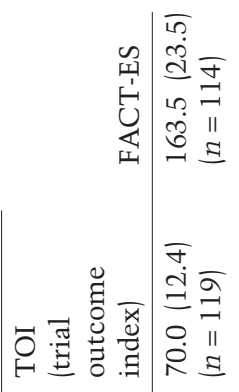

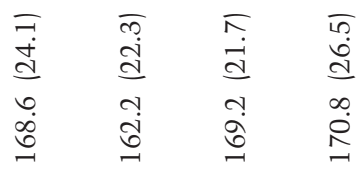

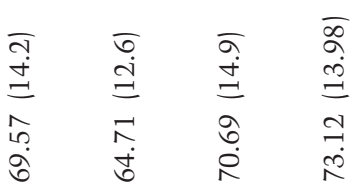

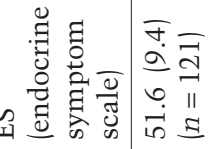

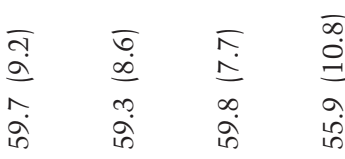

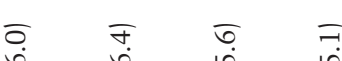

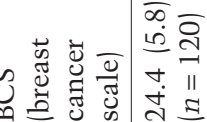

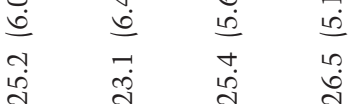

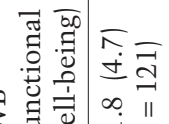

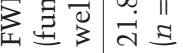

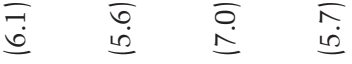

$\begin{array}{llll}\hat{0} & \infty & 0 & 0 \\ - & \stackrel{i}{+} & \text { ते }\end{array}$

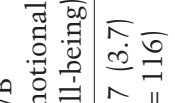

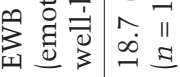

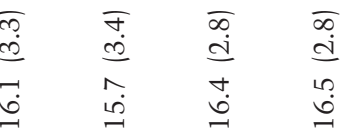

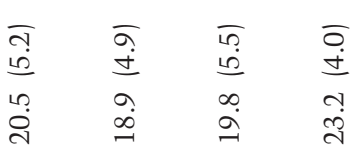

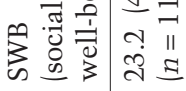

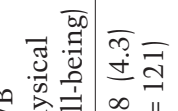

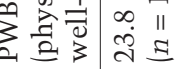

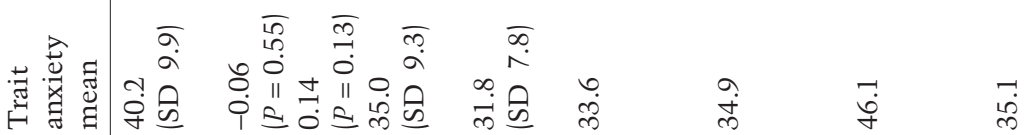

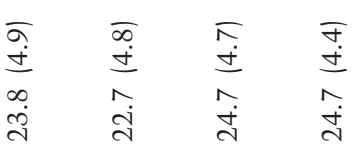

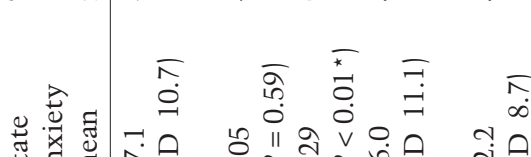

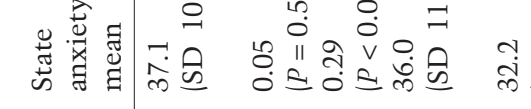

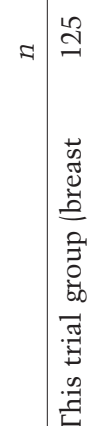

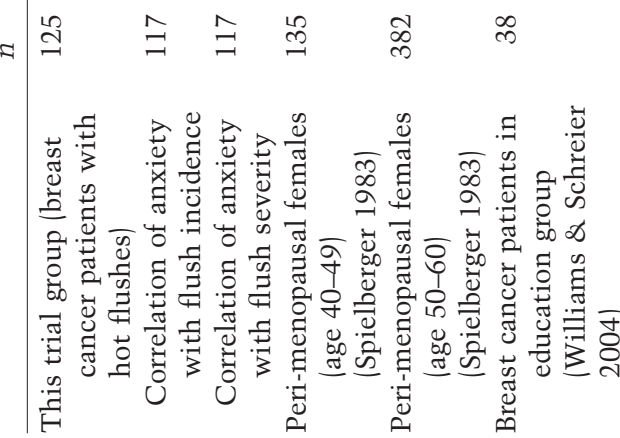

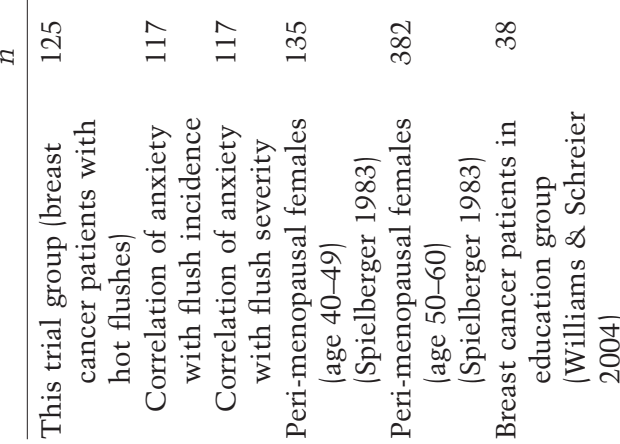

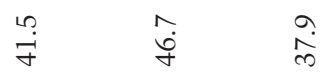

$\infty$

$\vec{\infty} \quad$ =

ஓ

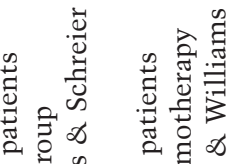

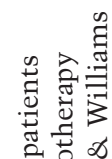

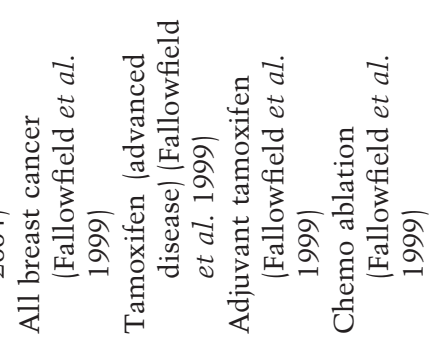

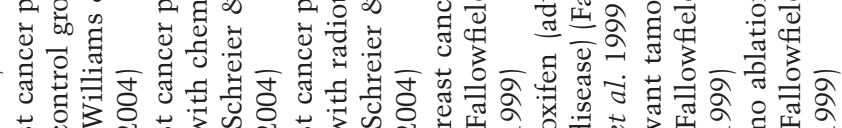

Фัँ

ติ 
cause of this is unclear, as no data were gathered as to the time of day that tamoxifen was taken, although the usual prescribing pattern was one $20 \mathrm{mg}$ tablet each morning. Anecdotally, some women claim that splitting the dose of tamoxifen, taking $10 \mathrm{mg}$ in the morning and $10 \mathrm{mg}$ in the evening, reduces flushing. One explanation might be that there is a short-term peak in tamoxifen after taking the tablet which exacerbates flushing. Women who take medication at night may then sleep through the peak or conversely, they may find that they have more disrupted nights. Further research is required to explain and confirm this phenomenon.

Although fewer flushes were recorded at night, sleep disturbance appears to be a major problem, with $72 \%$ of the women in this sample experiencing disturbed sleep as a consequence of their flushes in half of all the nights recorded. Although this might only be for a few minutes, it could also be several disruptions to a night and up to $6 \mathrm{~h}$ sleep lost in one night was recorded. The fact that sleep disruption happened night after night for years was likely to have a major impact on the lives of these women.

The relative contributions of different cancer treatments to precipitating menopause can be inferred from this sample. Where breast cancer and menopause coincided, $14 \%$ had chemotherapy only, $23 \%$ had tamoxifen only and 56\% had both chemotherapy and tamoxifen. These figures may be influenced by the treatment patterns in the hospitals where the sample was taken, as the use of chemotherapy and tamoxifen together may be much more frequent than either tamoxifen or chemotherapy alone. Nevertheless, these findings support evidence provided by previous authors, such as Biglia et al. (2003), that menopause can be caused by chemotherapy or tamoxifen alone and is much more likely when chemotherapy and tamoxifen are combined. There was no indication in this trial that the flushes that may have resulted from tamoxifen or chemotherapy were materially different from normal menopausal flushes, either in number or severity. This reinforces previous findings by Gupta et al. (2006). The median number of flushes for women having had oophorectomy was much higher (55 per week) than for other groups (33 per week). However, there were only three women in this group, which was insufficient for statistical analysis to be robust.

The fact that trait anxiety is higher in this group of women than in other women of the same age suggests that women with a more anxious personality may be more prone to experience troubling hot flushes. However, this was not borne out in further analysis as no relationship was seen between the number and severity of hot flushes and trait anxiety. There was a correlation between state anxiety and the severity of flushing, which might indicate that more severe flushes cause women to be more anxious. However, there was no clear link between anxiety and flushing.

The quality of life appeared to be affected in this group, as scores on the FACT-ES were worse than in other studies in women with breast cancer (Fallowfield et al. 1999). However, this low level of quality of life was nearly all accounted for by the scoring on the endocrine subscale, which suggests that the total quality of life score was heavily influenced by hot flushes. Differences in quality of life scores between groups were not great, however, and standard deviations were high, which suggest that these findings should be interpreted cautiously. Nevertheless, there is clearly much distress caused by flushes and night sweats, potentially causing a major problem in women's lives.

The sampling was a limitation in this study, as many women chose not to be included if they did not find flushes to be a problem, or if flushes were severe enough to require proven treatments. As a consequence, data were only collected from $39 \%$ women with flushes who were approached for the study, representing a mid-range of severity. There was also a high withdrawal rate from the study of $30 \%$ from initial recruitment, which was consistent with pilot work (Fenlon 1999). The reasons given for withdrawal suggest that perhaps women did not rate hot flushes as very important in comparison with cancer and cancer treatment. A further limitation of the study was that data were gathered primarily from Caucasian women.

\section{CONCLUSIONS}

Despite the fact that data presented here do not represent women who are either the worst or the least affected by hot flushes after breast cancer, there is clear evidence that hot flushes continue to be regarded as a problem for women long after treatment for breast cancer has been completed, causing distress, disrupted sleep and interference to daily life. There appears to be a morning peak in flushing in women taking tamoxifen, but there is no evidence that menopausal flushes are worse or more frequent due to the use of tamoxifen or chemotherapy when compared with normal menopausal flushes. Longitudinal data about the natural history of flushes after breast cancer is still lacking, and prospective, observational research is needed to provide women with accurate information about hot flushes and to establish a framework for future interventions. 


\section{ACKNOWLEDGEMENTS}

This work was supported by a grant from Cancer Research UK. None of the authors have any conflicts of interest in relation to this work.

\section{REFERENCES}

Barton D., La Vasseur B., Loprinzi C., Novotny P., Wilderwing M.B. \& Sloan J. (2002) Venlafaxine for the control of hot flashes: results of a longitudinal continuation study. Oncology Nursing Forum 29, 33-40.

Biglia N., Cozzarella M., Cacciari F., Ponzone R., Roagna R. \& Maggiorotto F. (2003) Menopause after breast cancer: a survey on breast cancer survivors. Maturitas 30, 45: 29-38.

Brady M.J., Cella D.F. \& Mo F. (1997) Reliability and validity of the Functional Assessment of Cancer Therapy - Breast quality of life instrument. Journal of Clinical Oncology 15, 974986.

Carpenter J.S. \& Andrykowski M.A. (1999) Menopausal symptoms in breast cancer survivors. Oncology Nursing Forum 26, 1311-1317.

Carpenter J.S., Gautam S., Freedman R.R. \& Andrykowski M. (2001) Circadian rhythm of objectively recorded hot flashes in postmenopausal breast cancer survivors. Menopause 8, 181188.

Carpenter J.S., Monahan P.O. \& Azzouz F. (2004) Accuracy of subjective hot flush reports compared with continuous sternal skin conductance monitoring. Obstetrics and Gynecology 104, 1322-1326.

Cohen S.M., Rousseau M.E. \& Carey B.L. (2003) Can acupuncture ease the symptoms of menopause? Holistic Nursing Practice 17, 295-299.

Dennerstein L., Dudley E.C., Hopper J.L., Guthrie J.R. \& Burger H.G. (2000) A prospective population-based study of menopausal symptoms. Obstetrics and Gynecology 96, 351-358.

Evans M.L., Pritts E., Vittinghoff E., McClish K., Morgan K.S. \& Jaffe R.B. (2005) Management of postmenopausal hot flushes with venlafaxine hydrochloride: a randomized, controlled trial. Obstetrics and Gynecology 105, 161-166.

Fallowfield L., Cella D., Cuzick J., Francis S., Locker G. \& Howell A. (2004) Quality of life of postmenopausal women in the Arimidex, Tamoxifen, Alone or in Combination (ATAC) Adjuvant Breast Cancer Trial. Journal of Clinical Oncology 22, 4261-4271.

Fallowfield L.J., Leaity S., Howell A., Benson S. \& Cella D. (1999) Assessment of quality of life in women undergoing hormonal therapy for breast cancer: validation of an endocrine symptom subscale for the FACT-B. Breast Cancer Research and Treatment 55, 188-199.

Fallowfield L.J., Bliss J.M., Porter L.S., Price M.H., Snowdon C.F., Jones S.E., Coombes R.C. \& Hall E. (2006) Quality of life in the intergroup exemestane study: a randomized trial of exemestane versus continued tamoxifen after 2-3 years of tamoxifen in postmenopausal women with primary breast cancer. Journal of Clinical Oncology 24, 910-917.

Fenlon D. (1999) Relaxation therapy as an intervention for hot flushes in women with breast cancer. European Journal of Oncology Nursing 3, 223-231.

Fenlon D. (2008) Menopause after breast cancer: a randomised, controlled trial of relaxation training to reduce hot flushes. Journal of Pain and Symptom Management 35, 397-405.

Finck G., Barton D.L., Loprinzi C.L., Quella S.K. \& Sloan J.A. (1998) Definitions of hot flashes in breast cancer survivors. Journal of Pain and Symptom Management 16, 327-333.

Gupta P., Sturdee D.W., Palin S.L., Majumder K., Fear R., Marshall T. \& Paterson I. (2006) Menopausal symptoms in women treated for breast cancer: the prevalence and severity of symptoms and their perceived effects on quality of life. Climacteric 9, 49-58.

Harris P.F., Remington P.L., Trentham-Dietz A., Allen C.I. \& Newcomb P.A. (2002) Prevalence and treatment of menopausal symptoms among breast cancer survivors. Journal of Pain and Symptom Management 23, 501-509.

Hunter M.S. \& Liao K.L. (1995) A psychological analysis of menopausal hot flushes. British Journal of Clinical Psychology 34, 589-599.

Hunter M.S., Grunfeld E.A., Mittal S., Sikka P., Ramirez A.J. \& Fentiman I. (2004) Menopausal symptoms in women with breast cancer: prevalence and treatment preferences. PsychoOncology 13, 769-778.

McPhail G. \& Smith L.N. (2000) Acute menopause symptoms during adjuvant systemic treatment for breast cancer: a casecontrol study. Cancer Nursing 23, 430-443.

Miller H.G. \& Li R.M. (2004) Measuring hot flashes: summary of a National Institutes of Health workshop. Mayo Clinic Proceedings 79, 777-781.

Mokbel K. (2001) The physiological basis. In: Endocrine and Biological Therapy of Breast Cancer Into the Twenty-First Century (ed. Mokbel, K.), pp. 1-8. Petroc Press, Newbury, UK.

Schreier A.M. \& Williams S.A. (2004) Anxiety and quality of life of women who receive radiation or chemotherapy for breast cancer. Oncology Nursing Forum 31, 127-130.

Shen J., Andersen R., Albert P.S., Wenger N., Glaspy J., Cole M. \& Shekelle P. (2002) Use of complementary/ alternative therapies by women with advanced-stage breast cancer. BMC Complementary and Alternative Medicine 2.

Sloan J., Loprinzi C., Novotny P.J., Barton D.L. \& Lavasseur B.I. (2001) Methodologic lessons learned from hot flash studies. Journal of Clinical Oncology 19, 4280-4290.

Spielberger C. (1983) State-Trait Inventory for Adults: Sampler Set, Manual, Test and Scoring Key. Mind Gardens, Redwood City, USA.

Stanton A., Bernaards C.A. \& Ganz P.A. (2005) The BCPT Symptom Scales: a Measure of Physical Symptoms for Women Diagnosed With or at Risk for Breast Cancer. Journal of the National Cancer Institute 97, 448-456.

Stearns V., Beebe K., Iyengar M. \& Smith I. (2003) Paroxetine controlled release in the treatment of menopausal hot flashes: a randomized controlled trial. Journal of the American Medical Association 289, 2827-2834.

Van Gool A.R., Bannink M., Bontenbal M. \& Seynaeve C. (2005) Clinical experience with venlafaxine in the treatment of hot flushes in women with a history of breast cancer. Netherlands Journal of Medicine 63, 175-178.

Williams S.A. \& Schreier A.M. (2004) The effect of education in managing side effects in women receiving chemotherapy for treatment of breast cancer. Oncology Nursing Forum 31, E16E23.

Xydakis A.M., Sakkas E.G. \& Mastorakos G. (2006) Hormone replacement therapy in breast cancer survivors. Annals of New York Academic Science 1092, 349-360. 